\title{
POTENTIAL AYURVEDIC HERBS FOR MANAGEIMENT OF SEXUAL DYSFUNCTION
}

KEY WORDS:

\section{Ronalk Shah* \\ Kadamb Patel \\ Shabbir Moochhala}

RAV Research Pvt Ltd, Mumbai, Maharastra, India *Corresponding Author

School of Applied Science, Temasek Polytechnic, Singapore

Fifthsense Pte Ltd, Singapore Department of Pharmacology, Yong Loo Lin School of Medicine, National University of Singapore

Sexual dysfunctions affect the quality of life, erectile dysfunction (E.D.), premature ejaculation (PME) reduced desire, and failing to achieve orgasm are common sexual dysfunctions which have a widespread presence across global populations.

E Health professionals focusing on behavioural variables, such as physical exercise, body mass index (BMI) and leanness reported, men with a body BMI of greater than $28.7 \mathrm{~kg} / \mathrm{m} 2$ is expected to have a 30 per cent higher chance of developing erectile dysfunction. There are significant increases in sexual functions among subjects who undergo intensive dietary changes, including weight loss and regular exercise.

Treatment of erectile dysfunction includes oral therapy with phosphodiesterase type 5 inhibitors which have various side effects. Alternative herbal therapies are offering holistic products with little or no side effects for the management of sexual dysfunctions. Herbal products backed with clinical studies are widely accepted in the market place.

The review focuses on the use of ayurvedic herbs for management of sexual dysfunctions and summarized clinical trails outcomes of commercially available herbal products for the management of sexual dysfunction

\section{Introduction}

Sexual dysfunctions (S.D.) are one of the major disorders that are distinguished by changes in the pathophysiology of the sexual response cycle or in sexual desire that deters the individual or couple from deriving contentment from sexual activity (Laumann et al. 1999)

Sexual dysfunctions have harmful effects on the interpersonal relationships or quality of life of the individuals. However, the issue of Sexual dysfunctions remains a paradox considering the fair amount of taboo, uneasiness and seclusion that is associated with it. It also falls in the landmark of psychiatric disorders and other medical disorders which makes it demanding to the clinician

The typical sexual dysfunctions observed were erectile dysfunction (E.D.), premature ejaculation (PME) reduced desire, and failing to achieve orgasm. With the age rise, the studies reported the prevalence of E.D. ramps up. The rates were also proportionate across different study population around the globe. Studies in Asia recorded the prevalence of E.D. for ages $40-49$ years at $7 \%-15 \%$ and for ages $60-70$ at 39 $\%-49 \%$. Results from Australian studies showed prevalence in ages $40-49$ years at $5 \%-6 \%$ and in ages $50-59$ at $12 \%-13$ $\%$. Overall, the findings from North America, Latin America and Europe have produced similar outcomes (Lewis et al. 2011)

Studies have concluded the elevated prevalence of E.D. in the Asian as compared to the other regions. Further evaluation of the studies also showed that premature ejaculation was one of the most commonly elicited conditions with a higher prevalence in the Asian and North American clusters. The other dysfunctions reported were an inability to reach orgasm and dyspareunia. Overall, $28 \%$ of the males and $39 \%$ of the females reported at least one S.D. (Lewis RW 2013)

In India, Sathyanarayana (2015) reported $21.15 \%$ of male subjects suffering from sexual disorder; erectile dysfunction prevalence was $15.77 \%$.In $8.76 \%$ of male subjects, premature ejaculation was found prevalent. Relative to other age groups, male sexual illnesses were extremely prevalent in age groups of 41-50 and 51-60. Erectile dysfunction is low among age groups of 26-30 years, and the lowest among age groups of 5160. Cross-sectional and community-based study indicates the prevalence of erectile dysfunction shows an age-dependent mild rise. By the year 2025, the number of E.D. cases across the world will reach 322 million (Ayta et al. 1999)

Male sexual disorders were more among subjects with chronic medical illness compared to those without chronic medical illness. Many researchers have shown that the prevalence of sexual dysfunction increases with age, history of arthritis, allergy, heart disease, untreated ulcer, diabetes and smoking (Sathyanarayana et al.2015)

\section{Role of Nutrition and Lifestyle in Sexual Dysfunction}

Follow-up research by healthcare professionals found many behavioural variables, such as physical exercise and leanness correlated with erectile function. Men with a body mass index (BMI) of greater than $28.7 \mathrm{~kg} / \mathrm{m} 2$ is expected to have a 30 per cent higher chance of developing erectile dysfunction compared to people with a BMI of 25 or below. (Bacon et al.2003)

Higher rates of physical activity indicate a substantial decrease in erectile dysfunction prevalence. The prevalence of erectile dysfunction contributes directly to obesity and overweight. The findings of descriptive research indicated a baseline BMI of $28 \mathrm{~kg} / \mathrm{m} 2$ significantly predicts the longterm development of erectile dysfunction, while initially overweight participants persisted at a high risk of developing erectile dysfunction, given the weight loss follow-up (Esposito et al.2004)

A randomized controlled trial of 110 obese men with moderate erectile dysfunction with significant behavioural changes showed that approximately one-third of participants in the experimental group regained normal erectile function during the study. Such findings indicate that there are major increases in a sexual performance in people who undergo intensive dietary changes, including weight loss and regular exercise. (Rosen et al.2005)

Pharmacological Management of Sexual Dysfunction The most used therapy for the treatment of erectile dysfunction includes oral therapy with phosphodiesterase type 5 inhibitors (PDE5 inhibitor), such as sildenafil (Viagra $\AA$ ). However, some patients may not be able to tolerate PDE5 inhibitor therapy or may require a lower dose because 
of side-effects relating to vasodilation. The oral treatment has the potential side effects such as flushing, dyspepsia, gastrointestinal symptoms, induce hypotension, cause headaches, and nasal congestion, blurred vision, a rash and back pain (McVary KT 2007). An additional concern, when considering the frequent coexistence of erectile dysfunction and Cardiovascular disease is that PDE5 may result in coronary ischaemia (Jackson et al.2006).

Increased awareness among consumers of side effects of pharmacological drugs has lead consumers to look for alternative therapy with little or no side effects. Acceptance of herbal and alternative therapies is growing for the management of various diseases. There are well established herbal therapies which offer holistic approaches to improve male reproductive health.

\section{Traditional and Herbal Remedies for the Management of Sexual Dysfunction}

Procreation was a major moral issue, and social concerns and aphrodisiacs played a significant part in maintaining both male and female potency. The expression 'Aphrodisiac' derives its origin from the Greek goddess of beauty and love, the word 'Aphrodite.' An aphrodisiac is medically any natural agent or material capable of improving sexual efficiency (Shamloul, 2010) and may be of animal, plant, or mineral origin (Kotta et al., 2013). Chinese, Egyptian, Hindu and Roman communities are actively searching for drugs that can enhance physical power (Shah, 2002).

The Indian and Chinese shared a similar aphrodisiac trait as the Romans in believing that consuming an animal's sexual organ, for example, goat testicles, can boost man's sexual ability (Shah, 2002). On the contrary, primaeval Egyptians were using aphrodisiac medications which involved the application of oiled baby crocodile heart to the penis or ingestion of a combination of 37 ingredients which included pine, salt, and a watermelon (Smith, 1974;Nunn, 1996).

Table 1. Clinical studies of herbal products for sexual dysfunctions

\begin{tabular}{|c|c|c|c|}
\hline No & Author & Product Name / Ingredients & Clinical studies results \\
\hline 1. & Ledda A. et al. (2010) & Prelox (L-Arginine and Pycnogenol) & $\begin{array}{l}\text { Prelox shows significant } \\
\text { Improvement in erectile function }\end{array}$ \\
\hline 2. & Kulkarni M.P et al. (2011) & $\begin{array}{l}\text { Asparagus adscendens, Withania somnifera, Mucuna } \\
\text { pruriens and Tribulus terrestris, }\end{array}$ & $\begin{array}{l}\text { Product was more effective than } \\
\text { placebo }\end{array}$ \\
\hline 3. & Shah G. R et al. (2012) & $\begin{array}{l}\text { VigRX (T. terrestris vine, Ginkgo biloba leaf, Panax } \\
\text { ginseng root (Crataegus rivularis berry leaf, Bioperine } \\
\text { Serenoa repens berry, and Turnera diffusa) }\end{array}$ & $\begin{array}{l}\text { VigRX was effective in improving } \\
\text { sexual functions in men }\end{array}$ \\
\hline 4. & Feng X. T et al. (2012) & Yidin (a combination of 15 Traditional Chinese herbs) & \begin{tabular}{|l} 
Yidin showed significant \\
Improvement in diabetic patients ED
\end{tabular} \\
\hline 5. & $\begin{array}{l}\text { Punyawudho. B et al. } \\
\text { (2013) }\end{array}$ & $\begin{array}{l}\text { Cappra }{ }^{\circledR} \text { (Maxim, Cynomorius,, Cistanche Deserticola, } \\
\text { Cervus Nippon Temminck, Carthamus Tinctorius and } \\
\text { Epimedium Brevicornum) }\end{array}$ & $\begin{array}{l}\text { Cappra is useful for mild to moderate } \\
\text { ED }\end{array}$ \\
\hline 6. & Cai. T et al. (2013) & $\begin{array}{l}\text { IDIProst Gold (Crocus sativus, S. repens and Pinus bark } \\
\text { extract) }\end{array}$ & IDIProst Gold improves E.D. in men \\
\hline 7. & $\begin{array}{l}\text { Nishimatsu. H et al. } \\
(2014)\end{array}$ & $\begin{array}{l}\text { Leopin Royal (Cuscuta seed, Epimedium, Garlic, } \\
\text { Ginseng, Velvet antler and Bezoar tincture) }\end{array}$ & $\begin{array}{l}\text { Significant Improvement in symptoms } \\
\text { of ageing and ED }\end{array}$ \\
\hline 8. & Udani. J.K et al. (2014) & Biotropics (Eurycoma longifolia and Polygonum minus) & $\begin{array}{l}\text { Enhances sexual functions among } \\
\text { healthy subjects }\end{array}$ \\
\hline 9. & $\begin{array}{l}\text { Sansalone. S et al. } \\
\text { (2014) }\end{array}$ & $\begin{array}{l}\text { Tradamix TX1000 (L-Citrulline, L-Arginine, Alga } \\
\text { Ecklonia bicyclis and T. terrestris) }\end{array}$ & $\begin{array}{l}\text { Tradamix improves erectile, and } \\
\text { Tradamix improves erectile and } \\
\text { ejaculation functions in patients with } \\
\text { mild to moderate ED }\end{array}$ \\
\hline 10. & $\begin{array}{l}\text { Stanislavov. R et al. } \\
(2015)\end{array}$ & $\begin{array}{l}\text { Prelox }{ }^{\circledR} \text { (Pycnogenol, Roburins, L Arginine and L- } \\
\text { Citrulline) }\end{array}$ & $\begin{array}{l}\text { Restored erectile function to normal } \\
\text { after four weeks }\end{array}$ \\
\hline 11. & Hsieh 2016 & $\begin{array}{l}\text { AB SCIEX (Serpentes cnidium monnier, Piper nigrum, } \\
\text { Panax quinquefolium, Lepidium meyenii Walp, } \\
\text { Ophiocordyceps sinensis, , Rhodiola rosea and } \\
\text { Astragalus membranaceus) }\end{array}$ & $\begin{array}{l}\text { Enhanced effects were observed } \\
\text { among impotent patients }\end{array}$ \\
\hline
\end{tabular}

Aphrodisiacs are classified based on the therapeutic activity of substance into three groups: (i) those that increase sexual arousal and desire; (ii) those that increase sexual potency through the effectiveness of an erection; and (iii) those that increase sexual pleasure (Sandroni, 2001; Kotta et al., 2013).

People who have erectile dysfunction have continued to explore aphrodisiac plants as an alternative therapy because of their efficacy, accessibility, affordability, and minimal side effects (Sabiu et al., 2016, Sabiu and Ashafa, 2017). Modern aphrodisiac drugs such as sildenafil citrate have reported triggering side effects such as loss of accommodation due to blurred vision, nasal congestion, urinary tract infections and stomach disorder (Kulkarni and Reddy, 1998; Lue, 2000).

\section{Medicinal Herbs with Validated Effects on Sexual Functions}

This section describes many time tested Ayurvedic and other traditional herbs, which have a long-standing reputation as a cure for sexual dysfunction. These herbs are an essential part of commercial formulations for improving sexual performance and fertility for males. Apart from these herbs large numbers of plants have also been tested and evaluated for effect on sexual functions and reproductive parameters, Thakur et al. 2014 complied a comprehensive description and names of these herbs

Based on tradition and culture, many multi herbs formulations emerged across the world; these formulations are clinically examined. Over the decades many such multiherb formulations are commercialized or E.D. with varying degrees of success. Clinical studies support most potent commercial-multiherb aphrodisiacs products available in the current market. Each product has a specific mechanism of actions which are well accepted by scientific communities. Increasing market needs for alternative medicine for sexual disorder will fuel more innovation, and companies are responding with investment in herbal science research and development worldwide. Table 1 compiles commercial herbal products based on clinical studies 
Green Love (Fructus schisandrae Euphoria longana Panax Green love was effective for treating mild \begin{tabular}{l|l|l} 
(2017) & quinquefolius, Rhizoma dioscoreae, Lyceum barbarum, & to moderate ED
\end{tabular}

3. Hussain. S.A et Plantago ovate, Eurycoma longifolia, Chlorophytum \begin{tabular}{l|l} 
al. (2018). & borivilianum, T. Anders, Acacia senegal, Astragalus
\end{tabular} membranaceus, Mimosa pudica, Bombax ceiba, Hygrophila sperms and a $154 \%$ increase in semen spinosa and Mucuna pruriens,

\section{CONCLUSION}

Sexual function is an integral component of quality of life and is essential for human subjective well-being. Sexual disorders are common, and mood, health and interpersonal functioning are adversely affected. Sexual problems play an important part in male erectile dysfunction and sexual arousal.

Successful treatment of sexual dysfunction may improve not only sexual relationships but also the overall quality of life. Thus, this review has dealt with various alternative approaches by which the medicinal plants are reaching out as an alternative therapy for sexual health

Rich knowledge of Ayurveda; Traditional Chinese Medicine and medicinal plants and herbs from Unani have been aiding in health care since ancient times. People around the world have used herbal medical goods for thousands of years. Medicinal plants and herbs are an essential aspect of the different cultures to cure male infertility problems or to cure reproductive disorders.

Over the past decade, interest in drugs derived from plants increased expressively.

Universally, general populations are taking charge of their management of health or disease. A significant proportion of consumers are adopting alternative "holistic" treatments, mainly herbal or phytopharmaceutical products, to treat a variety of health conditions.

The search for herbal health supplement from medicinal plants escalated probably because of its fewer side effects, its ready availability, and affordability. Allopathy drugs and treatments have limited efficacy, unpleasant side effects, and contraindications in certain disease conditions.

While reviewing different factors that regulate the sexual activity, this analysis discusses a number of medicinal plants and herbs that may theoretically be helpful in the treatment of sexual dysfunctions. In this analysis, all medicinal plants and herbs display important pharmacological activity.

Demands of herbal aphrodisiacs require scientific and clinical studies to understand their effects on humans and their safety profile. These drugs are standardized herbal preparations consisting of complex mixtures of one or more plants called phytomedicines or chemical compounds derived from plants. Medicinal plants are contributing around $25 \%$ of all modern medicines are directly or indirectly.

In the last decade, clinical evaluation of many new commercial multi-herbal formulations addressing sexual health is serving to understand exact mechanisms of action, safety profile, and drug interaction. Such detailed scientific studies create affirmative acceptance of commercial multiherbal products these products

The findings of this analysis showed many medicinal plants and herbs that are common for the treatment of impotence through diverse cultures and practices. The results of traditional and medieval literature, as well as modern medicine records accompanied by medical and clinical studies, establish new possibilities for herbal health supplements

\section{REFERENCES:}

1. Ayta IA, McKinlay JB, Krane RJ. The likely worldwide increase in erectile dysfunction between 1995 and 2025 and some possible policy consequences. BJU Int. 1999;84:50-56

2. Bacon CG, Mittleman MA, Kawachi I, et al. Sexual function in men older than 50 years of age: results from the Health Professionals Follow-up Study. Ann Int Med.2003;139(3):161-168

3. Esposito K, Giugliano F, Di Palo C, et al. Effect of lifestyle changes on erectile dysfunctionin obese men: a randomized controlled trial. JAMA. 2004;291(24):2978-2984

4. Feng XT, Qin CB, Leng J, et al. Yidiyin, a Chinese herbal decoction, improves erectile dysfunction in

5. diabetic patients and rats through the NO-cGMP pathway. Biosci. Biotechnol. Biochem., 76:257-263,2012.

6. Herwig, J. Greilberger, M.G. Greilberger, P.W. Weibl,2 - The herbal composition Green Love ${ }^{8}$ improves erectile function in patients with erectile dysfunction: A pilot study to evaluate effectiveness and safety,European Urology Supplements, Volume 16, Issue 11,2017

7. Hussain, S. A., Hameed, A., Nasir, F., Wu, Y., Suleria, H. A. R., \& Song, Y. (2018). Evaluation of the spermatogenic activity of polyherbal formulation in oligospermic males. BioMed research international, 2018

8. Jackson G, Rosen RC, Kloner RA, et al. The second Princeton consensus on sexual dysfunction and cardiac risk: new guidelines for sexual medicine. J Sex Med. 2006;3(1):28-36

9. Lewis RW.Epidemiology of sexual dysfunction in Asia compared to the rest of the world. Asian J Androl 2011;13:152-8)

10. Lewis RW. A critical look at descriptive epidemiology of sexual dysfunction in Asia compared to the rest of the world- $A$ call for evidence-based data. TranslAndrolUrol 2013;2:54-60)

11. Laumann EO, Paik A, Rosen RC. Sexual dysfunction in the United States: Prevalence and predictors.JAMA 1999;281:537-44

12. McVary KT.Erectile dysfunction. New Eng J Med. 2007;357(24):2472-2481

13. Rosen RC, Friedman M, Kortis JB. Lifestyle management of erectile dysfunction: the role of cardiovascular and concomitant risk factors. Am J Cardiol.2005;96(12B):76M-79M

14. Sathyanarayana Rao TS, Darshan MS, Tandon A. An epidemiological study of sexual disorders in South Indian Rural population. Indian J Psychiatry 2015;57:150-7

15. Jani, D. K. (2007). Comparative Clinical Study on Anacyclus pyrethrum and Spilanthus acmella as Akarakarabha in Erectile Dysfunction and Premature Ejaculation. Shodha Samagya, 1(04).

16. Ledda A, Belcaro G, Cesarone MR, Dugall M, Schonlau F. Investigation of a complex plant extract for mild to moderate erectile dysfunction in a randomized, double-blind, placebo-controlled, parallel-arm study. BJU Int. 2010;106(7):1030-3.

17. Kulkarni, M.P., Shinde, B.S., Chaudhari, M.K., Avhad, G., Pensalwar, S.V. Prasad, B.V., Deshpande, M.K., \& Rosenbloom, R.A. (2011). Efficacy and Safety of Two Polyherbal Combinations : E-MAH and EMA-HP in Male Sexual Dysfunction.

18. Shah, G. R., Chaudhari, M. V., Patankar, S. B., Pensalwar, S. V., Sabale, V. P., \& Sonawane, N. A. (2012). Evaluation of a multi-herb supplement for erectile dysfunction: a randomized double-blind, placebo-controlled study. BMC complementary and alternative medicine, 12(1), 155.

19. Feng, X. T., Qin, C. B., Leng, J., Tang, Q. L., Shi, H., Zhai, L. N., \& Li, S. L. (2012) Yidiyin, a Chinese herbal decoction, improves erectile dysfunction in diabetic patients and rats through the NO-cGMP pathway. Bioscience, biotechnology, and biochemistry, 76(2),257-263.

20. Punyawudho, B., Puttilerpong, C., Wirotsaengthong, S., \& Aramwit, P. (2012). A Randomized, Double-Blind, Placebo-Controlled Crossover Study of Cappra ${ }^{\circledR}$ for the Treatment of Mild or Mild to Moderate Erectile Dysfunction in Thai Male.

21. Cai,T., Morgia, G., Carrieri, G., Terrone, C., Imbimbo, C., Verze, P., \& IDIProst $₫$ Gold Study Group. (2013). An improvement in sexual function is related to better quality of life, regardless of urinary function improvement: results from the IDIProst@ Gold Study. Archivio Italiano di Urologia e Andrologia, 85(4), 184-189.

22. Nishimatsu H, Kitamura T, Yamada D, Nomiya A, Niimi A, Suzuki M, et al. Improvement of symptoms of aging in males by a preparation LEOPIN ROYAL containing aged garlic extract and other five of natural medicines comparison with traditional herbal medicines (Kampo). Aging Male. 2014;17:112-6.

23. Udani JK, George AA, Musthapa M, Pakdaman MN, Abas A. Effects of a proprietary freeze-dried water extract of Eurycoma longifolia (Physta) and polygonum minus on sexual performance and well-being in men: a randomized, double-blind, placebo-controlled study. Evid Based Complement Alternat Med. 2014;2014:179529.

24. Stanislavov R, Nikolova V, Rohdewald P. Improvement of erectile function with Prelox: a randomized, double-blind, placebo-controlled, crossover trial. Int J Impot Res. 2008;20:173-80

25. Paulis G, Cavallini G, Brancato T, Alvaro R. Peironimev-Plus $\AA$ in the treatment of chronic inflammation of tunica albuginea (Peyronie's disease). results of a controlled study. Inflamm Allergy Drug Targets. 2013;12:61-7.

26. Stanislavov R, Rohdewald P. Improvement of erectile function by a combination of French maritime pine bark and roburins with aminoacids. Minerva Urol Nefrol.2015;67:27-32.

27. European Urology Supplements,Volume 16, Issue 11, e2828

28. Hussain SA, Hameed A, Nasir F, Wu Y, Suleria HAR, Song Y. Evaluation of the spermatogenic activity of polyherbal formulation in oligospermic males. BioMed Res Int 2018. 